\title{
DEVELOPMENT OF ALTERNATIVE PROJECTILE TO DEACTIVATE AN IMPROVISED EXPLOSIVE DEVICE - PIPE BOMB
}

The article describes a possibility of dealing with the problem represented by an improvised explosive device in the form of a pipe bomb so that the problem may be solved quickly and reliably, i.e. so that the pipe bomb may be deactivated without explosion. The article describes the development of an alternative projectile that will replace the water content in the water gun; thus it will make it possible to remove metallic end caps closing pipe bombs so that the bombs can be disassembled without explosion, and subsequently to subject the dismantled parts to forensic examination to detect a designer of the improvised pipe bomb.

Key words: Improvised explosive device, pipe bomb, alternative projectile, water gun

\section{Introduction}

To the most insidious improvised explosive devices in bomb disposal practice belong those that contain so-called fragmenting components, such as various metallic subjects in the form of beads, rollers, small nuts and nails embedded into an explosive material and so-called pipe bombs. A pipe bomb is a metallic pipe filled with an explosive material in the form of high explosive, primary explosive, most frequently homemade propellant, or pyrotechnic composition.

The explosive material that is enclosed in a casing and brought to detonation usually causes the rupture of the casing and spray of its particles - fragments that then have destructive effects. This is called the fragmentation, or splinter effect of explosion [1].

For instance, fragments from the exploding metallic pipe bomb, in which a rapid explosive material was used, have the velocities equal approximately to the velocity of a projectile from a military riffle within the distance of several meters from the point of detonation, i.e. about $700-900 \mathrm{~m} / \mathrm{s}$; they move on their deadly trajectories straight as far as a barrier. They either reflect from the barrier, or enter into it, or penetrate through it. If they do not reach the barrier within a distance of about $100 \mathrm{~m}$, then their velocity will decrease and they will fall to the ground [1]. These fragments may directly endanger the bomb disposal specialist even if protected by a heavy bomb disposal suit, and may break through e.g. the frontal part of the helmet protected only by reinforced and hardened plexiglass. The front of this part of the suit has the lowest splinter protection coefficient, and in case of breaking through it, the specialist's face and/or hands that are protected only partly by a so-called ballistic overlap, see Fig. 1, may be injured [5]. Splinters of the metallic covering of the pipe bomb casing, where rapid explosives exploded
- e.g. high explosives, are owing to the action of huge temperatures and pressure during explosion twisted, torn, deformed and sharpedged. When a slow explosive is used - e.g. a propellant, splinters of larger size are formed on the contrary; they are not deformed, narrowed and sharp-edged so much. About one half of total explosion energy released by explosion will be consumed for rupturing the metallic covering of the casing itself. However, if the strengthened casing containing the rapid, or slow explosive material was cut, or crimped regularly, then final fragments will have the thus formed shape, size and corresponding weight and kinetic energy.

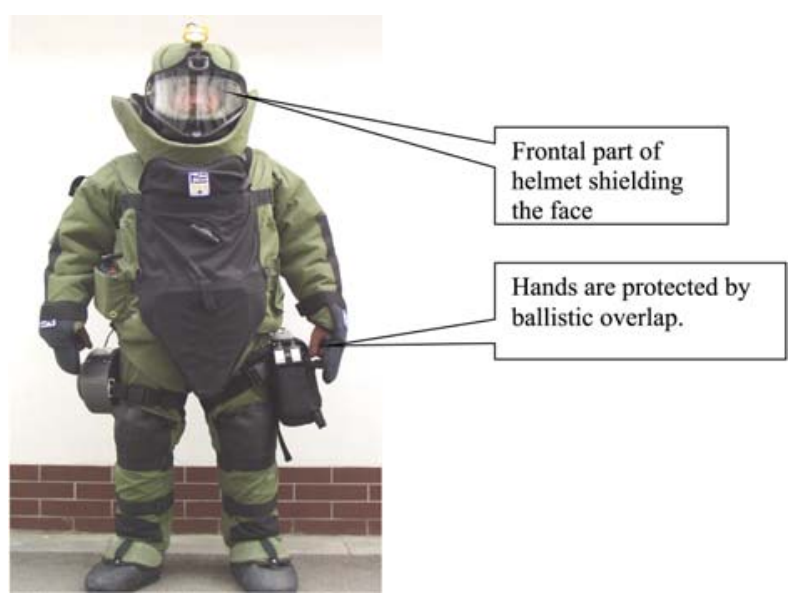

Fig. 1 EOD-8 heavy bomb disposal suit

In this way, substantially improved splinter effects will be obtained as well. As already mentioned at the beginning, if however the explosive article consists of an explosive material, into which

\footnotetext{
* Stanislav Lichorobiec,

VSB - Technical University of Ostrava, Department of Safety Management, Ostrava - Vyskovice, Czech Republic,

E-mail: stanislav.lichorobiec@vsb.cz
} 
small metallic subjects are embedded, e.g. beads from bearings, small nuts or nails, then a considerable so-called shrapnel effect will be achieved [2]

Such insidious improvised explosive devices can be secured against manipulation in the case of their detection, and their explosion can be timed. For bomb disposal specialists this is an indication that in the vicinity of them it is not advisable to stay. In the course of pipe bomb disposal it is necessary to work quickly, effectively, and to avoid explosion. For this reason, the identification methods and the disposal process itself must be shortened to minimum.

Whereas for the identification of a pipe bomb various means can be used, including a portable X-ray device, when identification photographs of a specific structure can be obtained in a very short time, the process of deactivation and disposal is not so simple.

Mostly it is the case of a metallic pipe closed at both ends with metallic end caps. The initiation of explosive filler is made through

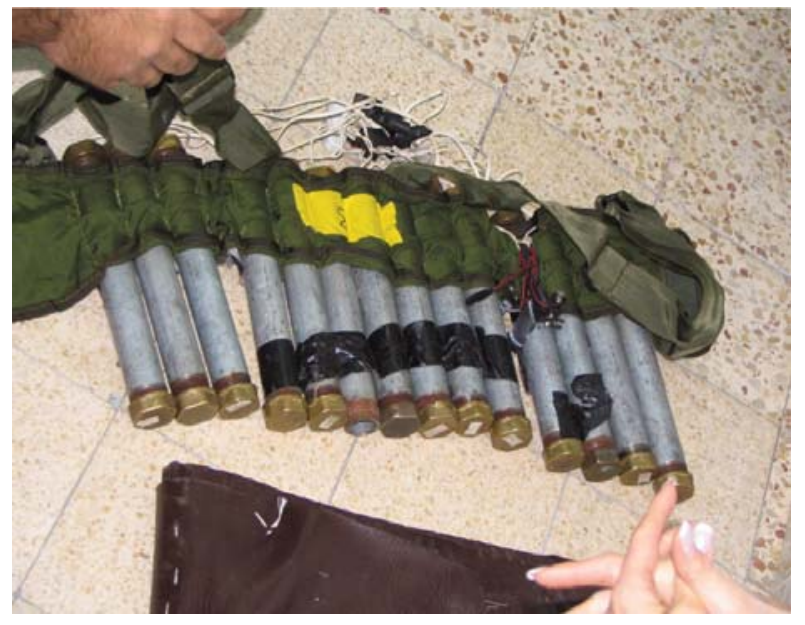

Fig. 2 Body belt of Israeli suicide

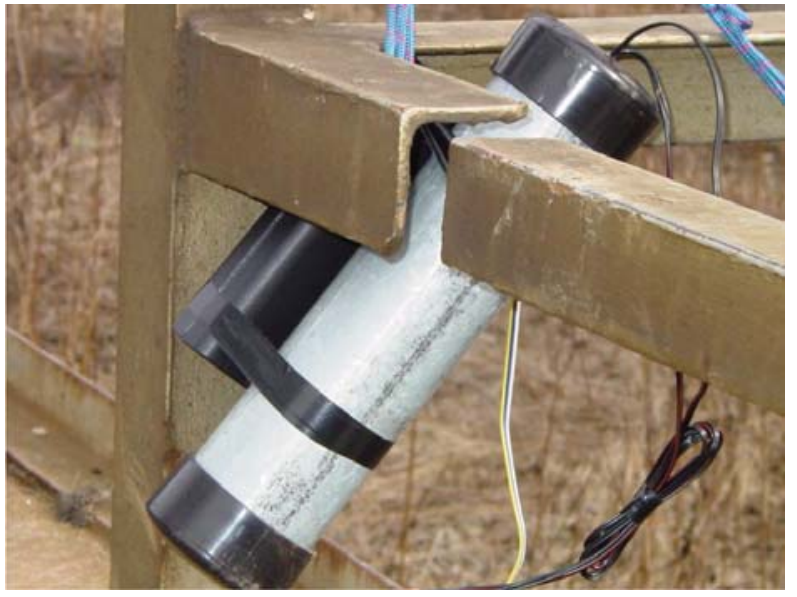

Fig. 4 Found pipe bomb wire inputs to the initiator itself either through the body of the pipe, or through one of the end caps. As for size, what is meant is a metallic pipe of the length of about $30 \mathrm{~cm}$, the diameter moving from 30 to $60 \mathrm{~mm}$ and the wall thickness ranging from 2 to $4 \mathrm{~mm}$. The explosive filler is very variable. A broad scale of explosives can be used, ranging from a propellant - black powder, pyrotechnic explosive compositions, through homemade very efficient primary explosives of the type of acetone peroxide - ACP, or hexamethylene triperoxide diamine - HMTD, to high explosives for military and industrial uses, e.g. delaborated trinitrotoluene - TNT from found military artillery ammunition, Permonex, or Danubit, stolen from some mine or quarry [3]. In Figs. 2 and 3 there are improvised explosive devices manufactured from pipe bombs used or found in Israel.

A similar pipe bomb was used not long ago in the Czech Republic as an improvised explosive device for the extortion of money under threat of the use of it as delayed-action bomb in places with high concentration of people. As for structural design, a steel pipe

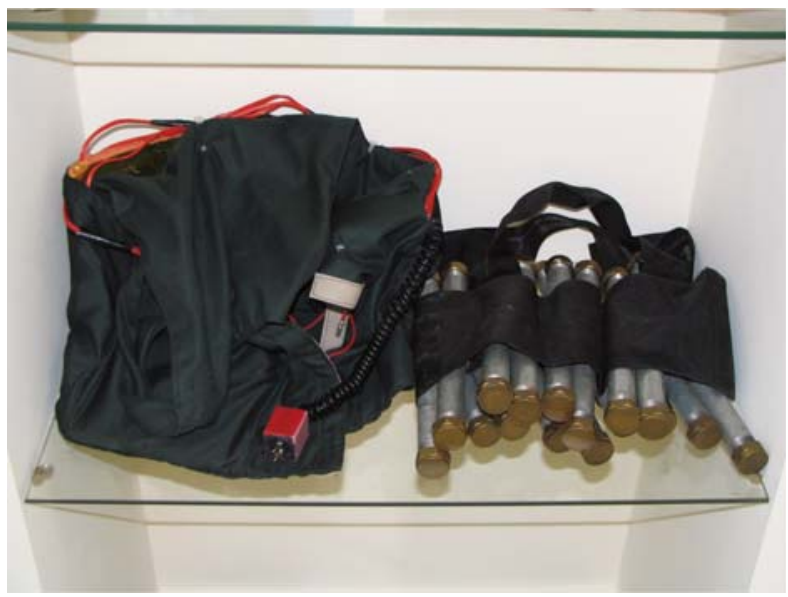

Fig. 3 Improvised explosive device from Israel

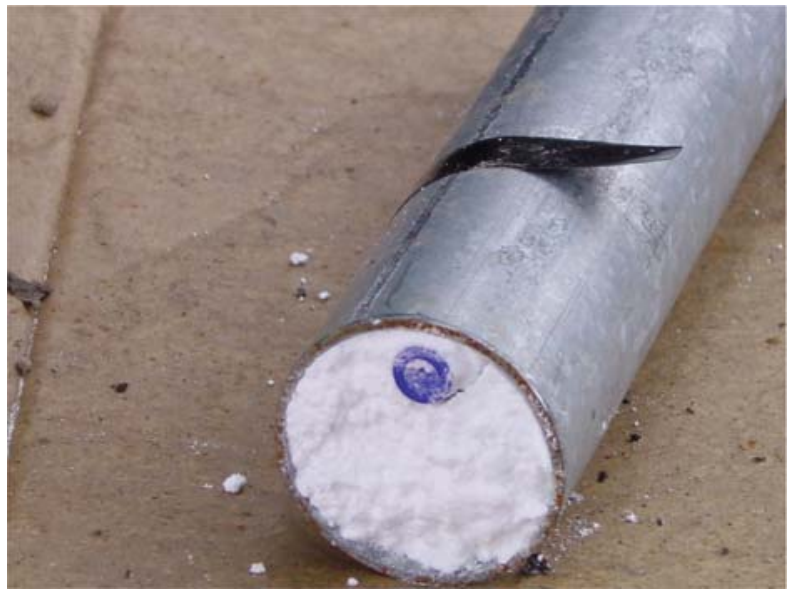

Fig. 5 After partial delaboration 
having the diameter of $62 \mathrm{~mm}$ and the wall thickness of $4 \mathrm{~mm}$ was taken; this was more than enough for the creation of sufficient fragmentation effect at explosion. It contained about $3 / 4 \mathrm{~kg}$ of homemade explosive - acetone peroxide (ACP). Fortunately, this metallic pipe was closed with relatively easy-to-dismantle plastic plugs of black colour, see Figs. 4 and 5.

I say fortunately because this explosive, which is one of very efficient primary explosives and which belongs to the group of organic peroxides, is made of highly volatile substances - acetone, hydrogen peroxide and hydrochloric acid, or sulphuric acid. This is a substance highly sensitive to mechanical stimuli, such as friction and impact. It is not very chemically stable; it is highly volatile and has the ability to recrystallize spontaneously, reacts to flame and spark, has a high initiation capacity and high brisance. Its detonation velocity moves in the range from 3000 to $5500 \mathrm{~m} / \mathrm{s}$, depending upon the density of a produced substance. It is a white, crystalline substance that explodes even when being manipulated carelessly, when the explosion of the whole volume occurs as a result of breaking merely one of the small crystals [4].

As already mentioned above, it was possible to remove the plastic coverings and to dissolve carefully the mentioned primary explosive in acetone. However, a question arose concerning the procedure if the pipe would have been closed with metallic screwedon end caps, because any attempt to screw them off could result, in the case of this explosive used as filler, in explosion, injury or death of the bomb disposal specialist.

\section{Development of Alternative Projectile}

Thus it was necessary to solve the problem of how in any way to remove remotely - to shoot metallic end caps down from the pipe bomb without the explosion of the pipe bomb, so that the improvised explosive device deactivated like that could be subject to forensic examinations to obtain evidence for a possible finding of its designer.

If we consider pipe bomb demobilization, two fast methods can be taken into account. As for the first method, an elongated cumulative charge will be used and the pipe will be cut by the cumulative jet; a possibility of detonation wave transmission to the used explosive embedded in the pipe may however occur, and most likely the explosion of the whole pipe bomb will take place [3]. As for the other method, we shall try to remove one of screwedon end caps and thus to dismantle the pipe bomb and to pour the explosive content out or to deactivate it in another non-explosive way. Attention was then paid to the latter variant - i.e. non-explosive removal of the end cap and thus preservation of possible relevant evidence for further forensic examination. As a tool for the removal of the end cap a water gun was chosen. It is used in the invasive dismantling of improvised explosive devices by means of the directional waterjet. The proper water filled projectile however was not able to throw off the screwed-on end caps. For this reason, an alternative projectile, which would be able without any risk to throw off the end cap without activation of the explosive filler of the pipe bomb and thus its explosion, began to be developed. Water guns of types VORO 98 of Slovak production and RADC - Royal Arms, of USA production, see Fig. 6, were chosen because in both the types as a driving filler for water ejection was used a designed special 12/70 gauge cartridge, used usually as charge in weapons of the type of shotgun; the cartridge can be modified advantageously for the design of an alternative projectile.

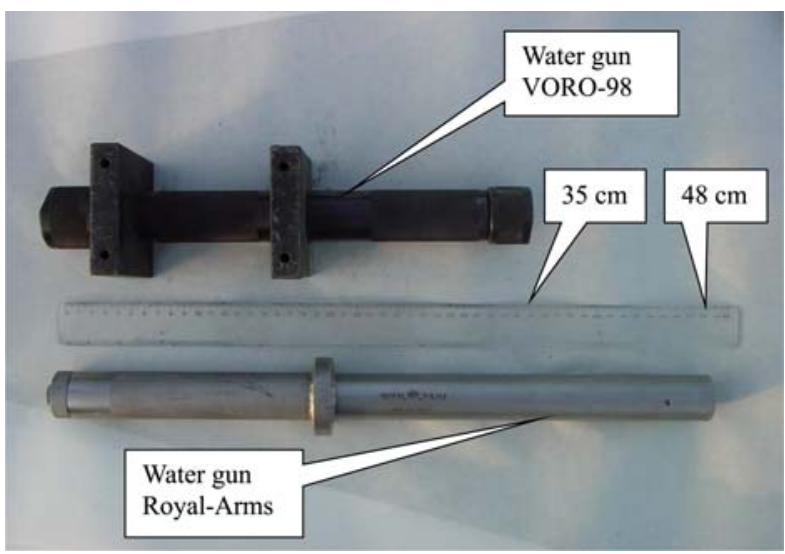

Fig. 6 Comparison of sizes of both water gun types

The alternative projectile must fulfil the following parameters:

- 100 per cent operating reliability in shooting down the screwedon metallic end cap in the case of pipe bomb,

- the powder filler sufficient for achieving the required operating pressure at a shot,

- non-vulnerability of the surroundings after work performed, i.e. a steel piece cannot be used as uniform projectile that can reflect non-controllably to any point in space, but such projectile is to be used that will disintegrate after work performed, i.e. - shot projectile,

- the shot projectile must be sufficiently compact so that the full burning out of the powder filler can occur and sufficient pressure can develop during the whole time of projectile flight inside the barrel, and thus a suitable muzzle velocity of this projectile, which will be then able to remove the metallic end cap, can be achieved, - absence of sparking in the course of shooting down the end cap, i.e. the minimization of risk of initiation of the explosive, or the igniting filler inside the pipe bomb,

- easy availability of all the materials that are necessary for the manufacturing of the alternative projectile.

As I have already mentioned, for the design of the alternative projectile, a 12/70 gauge cartridge was used, for which the cartridge chambers of both chosen water guns for shooting water were modified. This cartridge is adjusted to electrical initiation by initiator or to initiation by fire by means of timed safety fuse. The original powder filler for water shooting was used - powder Lovex; so that the alternative projectile may fulfil all determined parameters, a shot working filler composed of metallic microbeads used in metalworking plants to work metallic products by a so-called sand-blasting technology was selected after various experimental tests. 


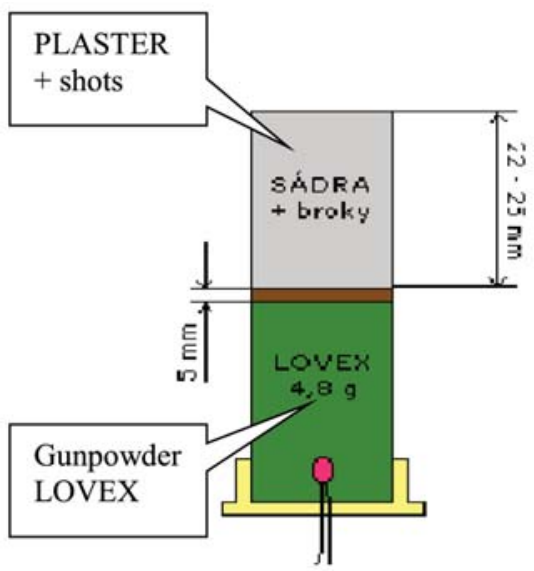

Fig. 7 Design of alternative projectile

As a binder, dental plaster was selected. It reliably binds steel microbeads together in one whole, compacts the entire projectile and when being shot, it ensures the non-sparking action of steel microbeads in the course of shooting down the metallic end cap of the pipe bomb.

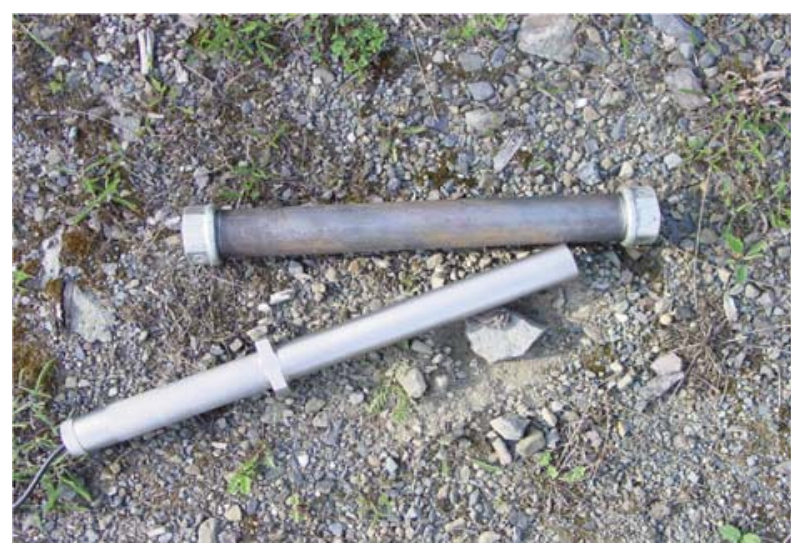

Fig. 9 Position of water gun Royal-Arms before shooting

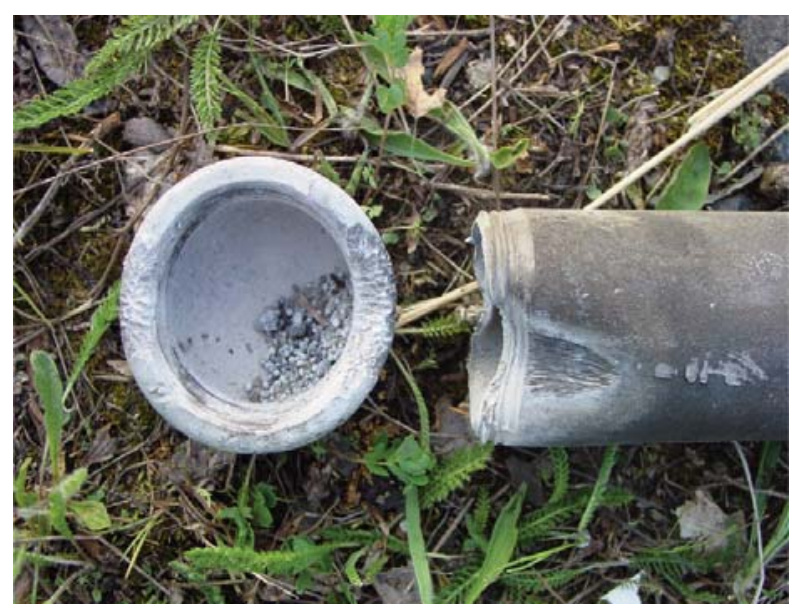

Figs. 10 and 11: Effective shooting down of the end cap from the pipe bomb

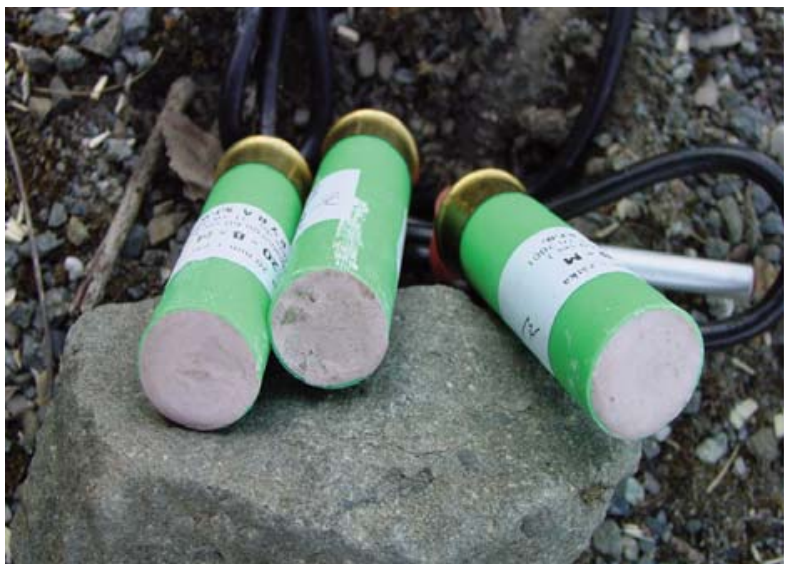

Fig. 8 Real alternative projectiles

As the best ratios of the mixture of plaster and microbeads for the formation of the alternative projectile the ratios of $1: 1$ for the test projectile AS-1 and of $1: 2$ for the test projectile AS-2 were selected. A diagram of structural design and real manufactured alternative projectiles can be seen in Figs. 7 and 8.

For the imitation of the pipe bomb in tests, common water pipes of the length of $30 \mathrm{~cm}$ and the diameter of $1 \frac{1}{1 / 2}(32 \mathrm{~mm})$ and $2 "(64 \mathrm{~mm})$ were used; for the mounting of metallic end caps minimally five threads were cut so that the end cap might hold on its whole thread surface.

Of several possible angles of approach of the water gun to the pipe bomb just before the shooting down of the end cap, an angle of $20^{\circ}$, see Fig. 9 turned out to be the most effective.

At the projectile developed like that and at the proved angle of approach of the water gun, the complete shooting down of the end cap was regarded as sufficiently well done task, see Figs. 10 and 11 .

In Figs 13 and 14, there are examples of insufficient result of shooting the end cap down, as given in Table 1 - no effect or the end cap not shot down, only a hole.

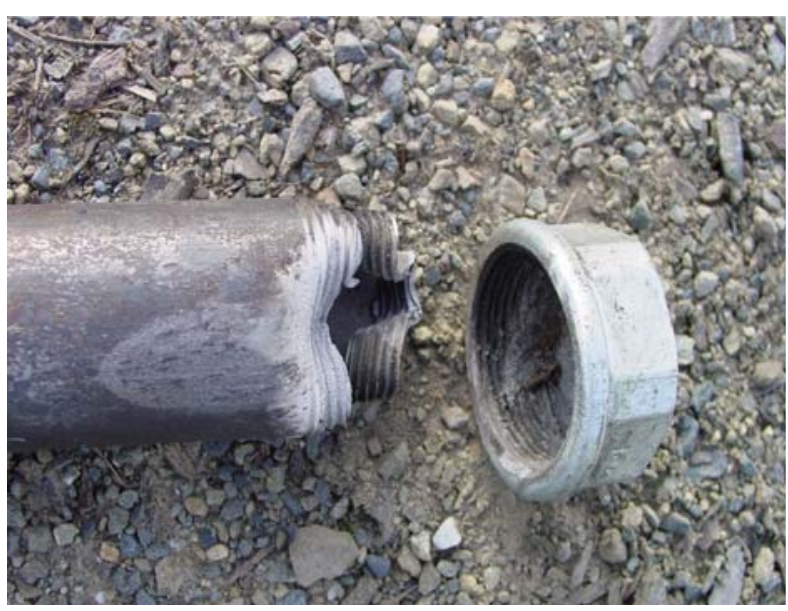



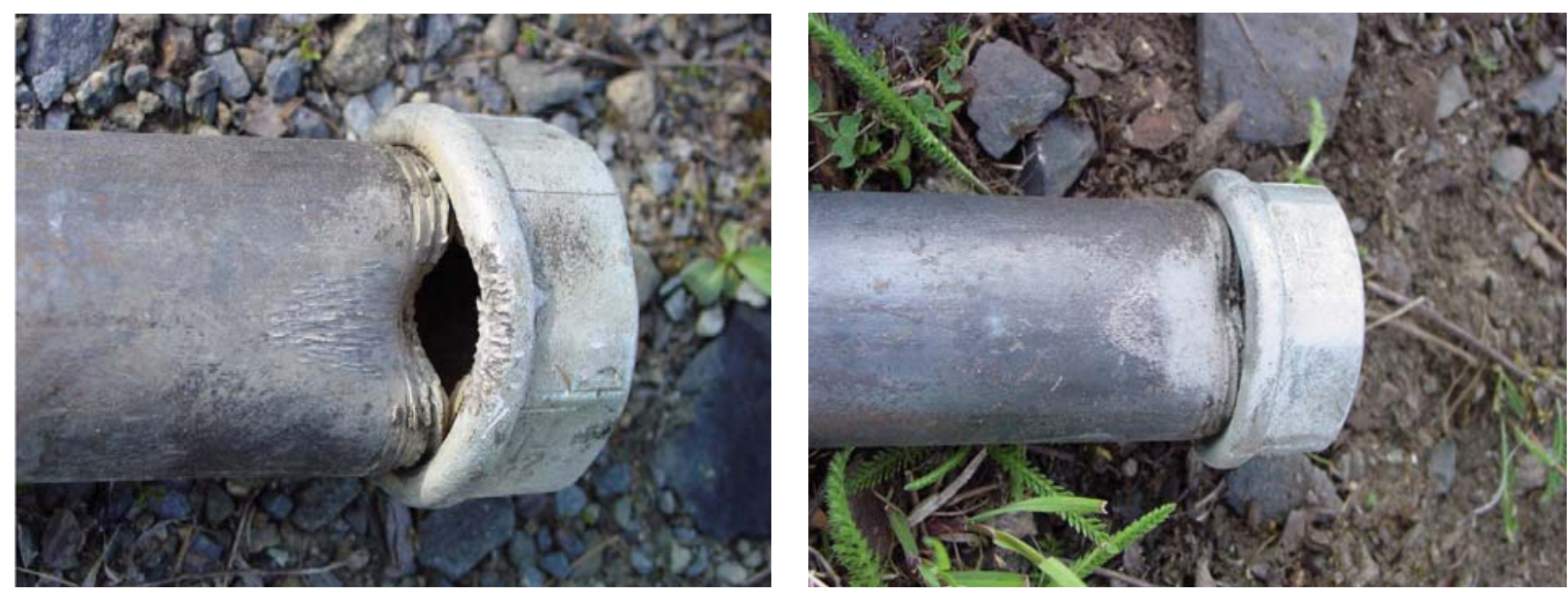

Figs. 13 and 14: Insufficient result of shooting down the end cap

Results that were achieved with the specific water guns and the developed alternative projectiles are compared in Table 1 and plotted in Graph 1.

Results of tests with water guns and specific types of alternative projectiles

\begin{tabular}{|c|c|c|c|c|}
\hline $\begin{array}{l}\text { Test } \\
\text { No. }\end{array}$ & $\begin{array}{l}\text { Type of } \\
\text { projectile }\end{array}$ & \begin{tabular}{|l} 
Type of \\
water gun
\end{tabular} & $\begin{array}{l}\text { Pipe } \\
\text { size }\end{array}$ & Result \\
\hline 1. & AS-1 & VORO-98 & $1 \frac{1}{1 / 2}$ & No effect \\
\hline 2. & AS-1 & VORO-98 & $1 \frac{1}{1 / 2}$ & End cap shot down \\
\hline 3. & AS-1 & VORO-98 & $1 \frac{1}{1 / 2} 2^{\prime \prime}$ & $\begin{array}{l}\text { End cap not shot down, } \\
\text { only a hole }\end{array}$ \\
\hline 4. & AS-1 & VORO-98 & $1 \frac{1}{1 / 2}$ & No effect \\
\hline 5. & AS-1 & VORO-98 & $1 \frac{1}{1 / 2}$ & No effect \\
\hline 6. & AS-1 & VORO-98 & $2^{\prime \prime}$ & $\begin{array}{l}\text { End cap not shot down, } \\
\text { only a hole }\end{array}$ \\
\hline 7. & AS-1 & VORO-98 & $2^{\prime \prime}$ & End cap shot down \\
\hline 8. & AS-1 & VORO-98 & $2^{\prime \prime}$ & End cap shot down \\
\hline 9. & AS-1 & VORO-98 & $2^{\prime \prime}$ & $\begin{array}{l}\text { End cap not shot down, } \\
\text { only a hole }\end{array}$ \\
\hline 10. & AS-1 & VORO-98 & $2^{\prime \prime}$ & No effect \\
\hline 11. & AS-1 & Royal-Arms & $1 \frac{1 / 2}{2 \prime}$ & End cap shot down \\
\hline 12. & AS-1 & Royal-Arms & $1 \frac{1}{1 / 2}$ & End cap shot down \\
\hline 13. & AS-1 & Royal-Arms & $1 \frac{1}{1 / 2}$ & End cap shot down \\
\hline 14. & AS-1 & Royal-Arms & $1 \frac{1}{1 / 2}$ & End cap shot down \\
\hline 15. & AS-1 & Royal-Arms & $1 \frac{1}{1 / 2}$ & End cap shot down \\
\hline 16. & AS-1 & Royal-Arms & $2^{\prime \prime}$ & End cap shot down \\
\hline 17. & AS-1 & Royal-Arms & $2^{\prime \prime}$ & End cap shot down \\
\hline 18. & AS-1 & Royal-Arms & $2^{\prime \prime}$ & End cap shot down \\
\hline 19. & AS-1 & Royal-Arms & $2^{\prime \prime}$ & End cap shot down \\
\hline 20. & AS-1 & Royal-Arms & $2^{\prime \prime}$ & End cap shot down \\
\hline
\end{tabular}

\begin{tabular}{|c|c|c|c|c|}
\hline $\begin{array}{l}\text { Test } \\
\text { No. }\end{array}$ & \begin{tabular}{|l} 
Type of \\
projectile
\end{tabular} & \begin{tabular}{|l}
$\begin{array}{l}\text { Type of } \\
\text { water gun }\end{array}$ \\
\end{tabular} & $\begin{array}{l}\text { Pipe } \\
\text { size }\end{array}$ & Result \\
\hline 21. & AS-2 & VORO-98 & $1 \frac{1 / 2^{\prime \prime}}{}$ & No effect \\
\hline 22. & AS-2 & VORO-98 & $1 \frac{1 / 2^{\prime \prime}}{}$ & $\begin{array}{l}\text { End cap not shot down, } \\
\text { only a hole }\end{array}$ \\
\hline 23. & AS-2 & VORO-98 & $1 \frac{1}{1 / 2}$ & End cap shot down \\
\hline 24. & AS-2 & VORO-98 & $1 \frac{1 / 2^{\prime \prime}}{}$ & End cap shot down \\
\hline 25. & AS-2 & VORO-98 & $1 \frac{1 / 2^{\prime \prime}}{}$ & End cap shot down \\
\hline 26. & AS-2 & VORO-98 & $2^{\prime \prime}$ & End cap shot down \\
\hline 27. & AS-2 & VORO-98 & $2^{\prime \prime}$ & End cap shot down \\
\hline 28. & AS-2 & VORO-98 & $2^{\prime \prime}$ & No effect \\
\hline 29. & AS-2 & VORO-98 & $2^{\prime \prime}$ & End cap shot down \\
\hline 30. & AS-2 & VORO-98 & $2^{\prime \prime}$ & $\begin{array}{l}\text { End cap not shot down, } \\
\text { only a hole }\end{array}$ \\
\hline 31. & AS-2 & Royal-Arms & $1 \frac{1 / 2^{\prime \prime}}{}$ & End cap shot down \\
\hline 32. & AS-2 & Royal-Arms & $1 \frac{1 / 2^{\prime \prime}}{}$ & End cap shot down \\
\hline 33. & AS-2 & Royal-Arms & $1 \frac{1 / 2^{\prime \prime}}{}$ & End cap shot down \\
\hline 34. & AS-2 & Royal-Arms & $1 \frac{1 / 2^{\prime \prime}}{}$ & End cap shot down \\
\hline 35. & AS-2 & Royal-Arms & $1 \frac{1 / 2^{\prime \prime}}{}$ & End cap shot down \\
\hline 36. & AS-2 & Royal-Arms & $2^{\prime \prime}$ & End cap shot down \\
\hline 37. & AS-2 & Royal-Arms & $2^{\prime \prime}$ & End cap shot down \\
\hline 38. & AS-2 & Royal-Arms & $2^{\prime \prime}$ & End cap shot down \\
\hline 39. & AS-2 & Royal-Arms & $2^{\prime \prime}$ & End cap shot down \\
\hline 40. & AS-2 & Royal-Arms & $2^{\prime \prime}$ & End cap shot down \\
\hline
\end{tabular}

\section{Conclusion}

From this research project on coping with the insidious improvised pipe bomb using a developed alternative projectile for water guns, several facts can be determined. 


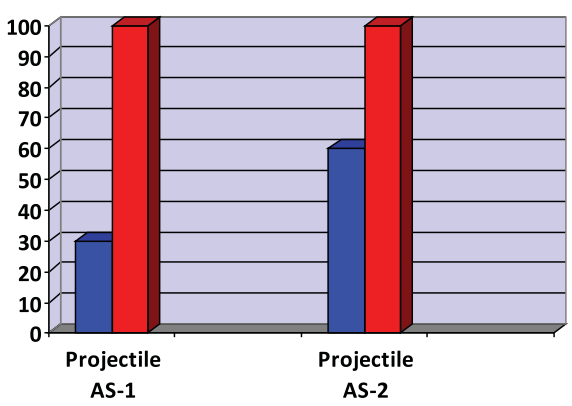

Graph 1: Representation of efficiency of water guns with specific types of projectiles

When a water gun VORO-98 is applied, it is possible to use merely special shot ammunition designated AS-2, when the hit rate, i.e. the complete opening of the pipe bomb and shooting down of the end cap can be determined to be about $60 \%$. In the case of the other type of used shot charge AS-1, any complete burning of powder filler of the charge will not occur, because the shot projectile is not probably consistent enough. Individual grains of unburned powder were found before the muzzle of the water gun. The cluster of shots in the barrel vibrates, its kinetic energy decreases, and thus only a slight or partial opening of the tube bomb takes place. The complete shooting down of the end cap occurred only in 30 per cent of cases.

In the case of water gun Royal-Arms, a 100 per cent success rate of both developed special shot fillers was achieved. At the presented mixing ratios between iron microbeads and plaster, the complete opening of tube bomb and the complete shooting down of end cap always occur. By using the mixture having the plaster/shot ratio of $1: 1$ or $1: 2$, the shot projectile produced like that was sufficiently consistent to cause the complete burning of powder filler, and thus sufficient pressure generation during the flight of shot cluster in the barrel. The sufficient muzzle velocity of the shot projectile was achieved; as a consequence the metallic end cap of the pipe bomb was shot down. This is essentially possible owing to the barrel of the water gun Royal-Arms which is sufficiently long for the longer acting of the pressure of gas on the shot projectile; the length being by $1 / 3$ greater than in the water gun VORO-98. Naturally, the fact that the interior of the barrel is hard-plated with chromium, and thus has much better quality, plays its role as well. In contrast to the water gun VORO-98, any ricochet of shots does not occur inside the barrel, the cluster of shots does not vibrate and thus does not lose energy.

Dental plaster reliably forms a compact whole with metallic shots, coats them, and produces a plaster cloud when being shot. Thus it prevents the development of sparks due to the impact of iron microbeads on the metallic body of the pipe bomb and limits the initiation of filler of the pipe bomb prone to bursting into flame or explosion as a result of this possible sparking.

In conclusion I state that if the pipe bomb is initiated through one of end caps, it is suitable to shot just this end cap, because together with the shooting down of this end cap, wires with the initiator are drawn away from the pipe bomb, i.e. outside the explosive filler of it. The risky handling of the initiator in the used explosive is avoided. This fact was often confirmed in tests. In addition, it can be stated that never the explosion of experimentally used filler of the pipe bomb occurred, regardless of whether some propellant, including black powder, pyrotechnic composition, or high explosive had been used. Homemade types of high explosives and primary explosives were not used in the tests owing to a high risk associated with explosive manufacturing and handling.

It follows from the above-presented knowledge and experience that as far as the deactivation of an improvised explosive device pipe bomb is concerned; a water gun Royal-Arms with both developed alternative projectiles is an absolutely reliable solution for bomb disposal specialists.

This contribution was prepared in the framework of dealing with the grant project of the Ministry of the Interior of the Czech Republic, Security Research Programme, under the No. MV0400511, "Vliv teroristickeho utoku na vybrane prumyslove technologie s nebezpecim vybuchu prachu" (Influence of Terrorist Attack on Selected Industrial Technologies with a Dust Explosion Hazard).

\section{References}

[1] URBAN, L., et al: Special Technology - part 1 (in Czech), Praha 1976

[2] HENRYCH, J.: Explosion Dynamics and her Exploitation (in Czech), Academia, Praha 1973

[3] DOJCAR, O., et al: Demolition Technology (in Czech), Montanex a.s., Ostrava 1996

[4] HANUS, M.: Improvise Explosives (in Czech), Univerzita Pardubice, 1996.

[5] HRAZDIRA, I., KOLlAR, M.: Police Pyrotechnics (in Czech), Ales Cenek, s.r.o., Plzen 2006. 